\title{
Seroprevalence of HIV, HBV, HCV and syphilis infections among blood donors at Gondar University Teaching Hospital, Northwest Ethiopia: declining trends over a period of five years
}

Belay Tessema ${ }^{1,5,7^{*}}$, Gizachew Yismaw ${ }^{2}$, Afework Kassu ${ }^{2,3}$, Anteneh Amsalu4 ${ }^{4}$ Andargachew Mulu ${ }^{2}$, Frank Emmrich ${ }^{5,6}$, Ulrich Sack ${ }^{5,6}$

\begin{abstract}
Background: Transfusion-transmissible infectious agents such as human immunodeficiency virus (HIV), hepatitis B virus (HBV), hepatitis $C$ virus ( $\mathrm{HCV}$ ) and syphilis are among the greatest threats to blood safety for the recipient. This study aimed to determine the seroprevalence, risk factors and trends of HIV, HBV, HCV and syphilis infections among blood donors over a period of five years at Gondar University Teaching Hospital, Northwest Ethiopia.
\end{abstract}

Methods: A retrospective analysis of consecutive blood donors' records covering the period between January 2003 and December 2007 was conducted. Logistic regression analysis was used to determine risk factors associated with HIV, HBV, HCV and syphilis infections.

Results: From the total of 6361 consecutive blood donors, 607 (9.5\%) had serological evidence of infection with at least one pathogen and $50(0.8 \%)$ had multiple infections. The overall seroprevalence of HIV, HBV, HCV and syphilis was $3.8 \%, 4.7 \%, 0.7 \%$, and $1.3 \%$ respectively. Among those with multiple infections, the most common combinations were HIV - syphilis 19 (38\%) and HIV - HBV 17 (34\%). The seropositivity of HIV was significantly increased among female blood donors, first time donors, housewives, merchants, soldiers, drivers and construction workers. Significantly increased HBV seropositivity was observed among farmers, first time donors and age groups of $26-35$ and $36-45$ years. Similarly, the seroprevalence of syphilis was significantly increased among daily labourers and construction workers. Statistically significant association was observed between syphilis and HIV infections, and HCV and HIV infections. Moreover, significantly declining trends of HIV, HCV and syphilis seropositivity were observed over the study period.

Conclusions: A substantial percentage of the blood donors harbour HIV, HBV, HCV and syphilis infections. Strict selection of blood donors and comprehensive screening of donors' blood using standard methods are highly recommended to ensure the safety of blood for recipient.

\section{Background}

The discovery of transfusion-transmissible infections (TTIs) has heralded a new era in blood transfusion practice worldwide with emphasis on two fundamental objectives, safety and protection of human life [1]. Blood safety remains an issue of major concern in transfusion medicine in Ethiopia where national blood transfusion

\footnotetext{
* Correspondence: bt1488@yahoo.com

${ }^{1}$ Department of Medical Laboratory Technology, College of Medicine and Health Sciences, University of Gondar, Gondar, Ethiopia
}

services and policies, appropriate infrastructure, trained personnel and financial resources are inadequate.

Human immunodeficiency virus (HIV), hepatitis B virus (HBV) and hepatitis $\mathrm{C}$ virus (HCV) are of great concern because of their prolonged viraemia and carrier or latent state. They also cause fatal, chronic and life-threatening disorders. Blood transfusion accounts for $5-10 \%$ of HIV infections in sub-Saharan Africa [2]. Similarly, 12.5\% of patients who received blood transfusion are at risk of posttransfusion hepatitis [3]. HBV is highly contagious and

\section{() Biomed Central}


relatively easy to be transmitted from one infected individual to another by blood transfusion, during birth, by unprotected sex, and by sharing needles and has a relatively higher prevalence in the tropics $[4,5]$. A study conducted in Addis Ababa, Ethiopia showed that HCV antibody prevalence was $0.9 \%$ and higher among HIVpositive compared to HIV-negative individuals (4.5\% vs. $0.8 \%$, respectively). Similarly, higher prevalence of $\mathrm{HCV}$ antibodies was seen among HIV-positive compared to HIV negative antenatal care attenders $(2.9 \%$ vs. $0.8 \%$, respectively), and sex workers (5.3\% vs. $1.3 \%$, respectively) [6].

Syphilis is also a systemic disease caused by Treponema pallidum which can be spread by sexual contact, blood transfusion and via vertical transmission [7]. In sub-Saharan Africa, syphilis remains a serious public health problem. Prevalence of active syphilis infection among African countries showed $12.8 \%$ in Tanzania [8], and $3.8 \%$ in Kenya [9]. A study conducted to assess the prevalence of infection with HIV, syphilis and HBV among Ethiopian blood donors in 1995 showed that the seroprevalence of HIV-1, syphilis and HBV was $16.7 \%$, $12.8 \%$ and $14.4 \%$, respectively [10].

The high prevalence of HIV, HBV, HCV and syphilis has heightened the problems of blood safety in Ethiopia. Thus, continuous monitoring of the magnitude of transfusion-transmissible infections in blood donors is important for estimating the risk of transfusion and optimizing donor recruitment strategies to minimize infectious diseases transmission. Therefore, this study was conducted to determine the seroprevalence, risk factors and trends of HIV, HBV, HCV and syphilis infections among blood donors at Gondar University Teaching Hospital in Northwest Ethiopia.

\section{Methods}

\section{Study design, setting and study subjects}

A retrospective analysis of consecutive blood donors' records covering the period between January 2003 and December 2007 was conducted at Gondar University Teaching Hospital. The hospital is a tertiary level teaching hospital that provides health service to over five million inhabitants in Northwest Ethiopia, and is located $727 \mathrm{Km}$ north from the capital city, Addis Ababa. Institutional ethical clearance was obtained from the research and publication committee of Gondar University. However, due to the nature of the study (retrospective review of blood donors' records), informed consent was not obtained from the study subjects.

Blood donors were either volunteers, or relatives or friends of patients and commercial donors who were recruited and paid by patients, their families, or friends to replace blood used or expected to be used for patients from the blood bank of the hospital. In the blood bank unit of the hospital, the first step in screening for potential blood donors is taking past medical history of the client. Individuals are required to give answers to a panel of questions on previous illnesses and medical conditions. Past history of blood transfusion and questions targeted to ascertain risky sexual behavior and practice are also part of the questionnaire. Apparently healthy subjects of age 17 to 65 years with body weight above 45 $\mathrm{kg}$ would qualify for donation. The medical and sociodemographic histories of the donors were recorded in the logbook and venous blood was collected in blood banking bags following standard procedures.

\section{Laboratory diagnosis for HIV 1 and 2}

Each donor's serum sample was screened for HIV-1 and HIV-2 using Vironostika HIV Uni-Form II Ag/Ab (BioMerieux, Boxtel, The Netherlands) following the manufacturer's instructions.

\section{Laboratory tests for $\mathrm{HBsAg}$ and $\mathrm{HCV}$ antibodies}

Sera were checked for the presence of hepatitis $B$ surface antigen (HBsAg) using ELISA, Hepanostika HBsAg (Murex Biotech Ltd, Dartford, UK). Similarly, IgG antibodies to HCV were detected using an ELISA technique (Murex anti-HCV version 4.0) according to the manufacturer's instructions.

\section{Laboratory diagnosis for syphilis}

Serum from all donors was tested for the presence of treponemal antibodies using rapid plasma reagin test (RPR) following the manufacturer's instructions (RPR, Wampole Laboratories, Princeton, N.J., USA).

\section{ABO blood grouping and Rhesus $(\mathrm{RH})$ typing}

$\mathrm{ABO}$ and $\mathrm{Rh}$ blood groups determinations were carried out on a slide using monoclonal blood grouping antisera; anti-A, anti-B, anti-AB, and anti-D (BIOTEC Laboratories Ltd, Great Britain).

\section{Statistical analysis}

Data were entered, cleaned and analysed using SPSS version 13 statistical package. To ensure the quality of data entered into the computer, two people independently cross-checked each entry. Differences in prevalence of HIV, HBV, HCV and syphilis for Socio-demographic variables were tested for significance using logistic regression. Moreover, linear regression was used to assess the statistical significance of trends in seroprevalence of these pathogens over the study period. P value less than 0.05 was considered statistically significant.

\section{Results}

\section{Demographic characteristics of donors}

As shown in Table 1, a total of 6361 consecutive blood donors were screened at Gondar University Teaching 
Table 1 Socio-demographic characteristics of blood donors at Gondar University Teaching Hospital in Northwest Ethiopia 2003-2007

\begin{tabular}{|c|c|}
\hline Characteristics & Number (\%) \\
\hline \multicolumn{2}{|l|}{ Age group (years) } \\
\hline $17-25$ & $3357(52.8)$ \\
\hline $26-35$ & $1686(26.5)$ \\
\hline $36-45$ & 757 (11.9) \\
\hline $46-55$ & $395(6.2)$ \\
\hline $56-65$ & $166(2.6)$ \\
\hline \multicolumn{2}{|l|}{ Gender } \\
\hline Male & $5592(87.9)$ \\
\hline Female & $769(12.1)$ \\
\hline \multicolumn{2}{|l|}{ Occupation } \\
\hline Daily labourer & $1769(27.8)$ \\
\hline Farmer & $1575(24.8)$ \\
\hline Student & $1347(21.2)$ \\
\hline Housewife & $212(3.3)$ \\
\hline Govt. employee & $599(9.4)$ \\
\hline Merchant & $333(5.2)$ \\
\hline Soldier & $47(0.7)$ \\
\hline Driver & $120(1.9)$ \\
\hline Construction worker & $343(5.4)$ \\
\hline Others & $16(0.3)$ \\
\hline \multicolumn{2}{|l|}{ Number of donation } \\
\hline First donation & $4372(68.7)$ \\
\hline Repeat donation & 1989 (31.3) \\
\hline \multicolumn{2}{|l|}{ ABO Blood groups } \\
\hline $\mathrm{O}$ & $2952(46.4)$ \\
\hline A & $1715(27.0)$ \\
\hline B & $1406(22.1)$ \\
\hline$A B$ & $288(4.5)$ \\
\hline \multicolumn{2}{|l|}{ Rhesus (RH) type } \\
\hline Positive & $5984(94.1)$ \\
\hline Negative & $377(5.9)$ \\
\hline
\end{tabular}

Hospital blood bank unit during the study period. Of these, $5592(87.9 \%)$ donors were males and 769 (12.1\%) were females. The median age of the study subjects was 25 years (range 17 - 65 years). Of all donors, 3357 (52.8\%) were in the age group of 17-25 years, $4372(68.7 \%)$ were first time donors, 2952 (46.4\%) were blood group O and 5984 (94.1\%) were Rhesus D (RH) positive. In addition, daily labourers (27.8\%), farmers (24.8\%) and students, more frequently Collage/University students (21.2\%) were constitute a major chunk of the blood donors. The relatively higher number of farmer and daily labourer donors may be due to the fact that farmers constitute a major portion of the general population and majority of the commercial blood donors are daily labourers.

\section{Seroprevalence of HIV, HBV, HCV and syphilis}

The overall seroprevalence rate of HIV, HBV, HCV and syphilis was $3.8 \%, 4.7 \%, 0.7 \%$ and $1.3 \%$ respectively (Table 2). Of all donated blood during the study period, 607 (9.5\%) had serological evidence of infection with at least one pathogen and $50(0.8 \%)$ had multiple infections. Among those with multiple infections, the most common combinations were HIV-syphilis 19 (38\%) and HIV - HBV 17 (34\%) (Table 3). As shown in Table 4, the seroprevalence of HIV was significantly increased among female blood donors $(\mathrm{P}<0.001)$ compared to male blood donors, first time donors $(\mathrm{P}<0.001)$ compared to repeat donors, and among housewives ( $\mathrm{P}<$ $0.001)$, merchants $(P<0.001)$, soldiers $(P=0.020)$, drivers $(\mathrm{P}=0.041)$ and construction workers $(\mathrm{P}=0.009)$ compared to students. The seroprevalence of syphilis was significantly increased among daily labourers $(\mathrm{P}=$ $0.001)$ and construction workers $(\mathrm{P}=0.013)$ compared to students. Similarly, the seropositivity of HBV was significantly increased among donors with the age groups of 26 - 35 and 36 - 45 years compared to the age group

Table 2 Trends of seropositivity of HIV, Syphilis, HBV and HCV among blood donors at Gondar University Teaching Hospital in Northwest Ethiopia 2003 - 2007

\begin{tabular}{|c|c|c|c|c|c|}
\hline Year & $\begin{array}{c}\text { Total screened } \\
\text { N }\end{array}$ & $\begin{array}{c}\text { HIV positive } \\
\text { N (\%) }\end{array}$ & $\begin{array}{c}\text { Syphilis positive } \\
\mathrm{N}(\%)\end{array}$ & $\begin{array}{c}\text { HBV positive } \\
\mathrm{N}(\%)\end{array}$ & $\begin{array}{c}\text { HCV positive } \\
\text { N (\%) }\end{array}$ \\
\hline 2003 & 1156 & $58(5.0)$ & $45(3.9)$ & $62(5.4)$ & $x$ \\
\hline 2004 & 1693 & $61(3.6)$ & $33(1.9)$ & $85(5.0)$ & $23(1.4)$ \\
\hline 2005 & 1187 & $47(4.0)$ & $1(0.1)$ & $63(5.3)$ & $7(0.6)$ \\
\hline 2006 & 1045 & $33(3.2)$ & $2(0.2)$ & $30(2.9)$ & $3(0.3)$ \\
\hline 2007 & 1280 & $40(3.1)$ & $2(0.2)$ & $58(4.5)$ & $2(0.2)$ \\
\hline Total & 6361 & $239(3.8)$ & $83(1.3)$ & $298(4.7)$ & $35(0.7)$ \\
\hline $\mathrm{p}$-Value of linear regression for trend & - & 0.021 & $<0.001$ & 0.061 & $<0.001$ \\
\hline
\end{tabular}

$\mathrm{N}=$ Number; $\mathrm{X}=$ Not done 
Table 3 Prevalence of co-infections of HIV, HBV, HCV and syphilis among blood donors at Gondar University Teaching Hospital in Northwest Ethiopia 2003-2007

\begin{tabular}{ccc}
\hline Co-infections & Number & Percent \\
\hline HIV - Syphilis & 19 & 38.0 \\
HIV - HBV & 17 & 34.0 \\
HIV - HCV & 4 & 8.0 \\
HBV - Syphilis & 7 & 14.0 \\
HBV - HCV & 2 & 4.0 \\
Syphilis - HCV & 1 & 2.0 \\
Total & $\mathbf{5 0}$ & $\mathbf{1 0 0}$ \\
\hline
\end{tabular}

greater than 45 years, farmers $(\mathrm{P}=0.005)$ compared to students and first time donors $(\mathrm{P}<0.001)$ compared to repeat donors (Table 5).

The prevalence rate of syphilis, $\mathrm{HBV}$ and $\mathrm{HCV}$ among HIV infected donors was $7.9 \%, 7.1 \%$, and $2.2 \%$ respectively, compared with the prevalence rate of $1.0 \%, 4.6 \%$ and $0.6 \%$ among HIV-seronegative donors. Furthermore, statistically significant association was observed between syphilis and HIV infection $(\mathrm{P}<0.001)$ (Table 4$)$, and $\mathrm{HCV}$ and HIV infection $(\mathrm{P}=0.002)$ (Table 5).
Trends of HIV, HBV, HCV and syphilis seroprevalence Significantly declining trends of HIV $(\mathrm{P}=0.021), \mathrm{HCV}$ $(\mathrm{P}<0.001)$ and syphilis $(\mathrm{P}<0.001)$ seroprevalence were observed over the five years study period. The seroprevalence of HIV was $5.0 \%$ in 2003 and decreased to $3.6 \%$ in 2004 and slightly increased to $4.0 \%$ in 2005 but subsequently decreased to $3.2 \%$ in 2006 and $3.1 \%$ in 2007. The seroprevalence of HBV was decreased from $5.4 \%$ in 2003 to $2.9 \%$ in 2006 and increased further to $4.5 \%$ in 2007 . HCV prevalence decreased steadily from $1.4 \%$ in 2004 to $0.6 \%$ in $2005,0.3 \%$ in 2006 , and $0.2 \%$ in 2007. Similarly, the prevalence of syphilis decreased progressively from $3.9 \%$ in 2003 to $1.9 \%$ in $2004,0.1 \%$ in 2005 and $0.2 \%$ in 2006 and 2007 (Table 2).

\section{Discussion}

In this study, significantly declining trends of HIV, HCV and syphilis seroprevalence were observed among blood donors over the study period. This finding is consistent with the observed declining trend of HIV seroprevalence in the general population in Ethiopia [11], declining trend of HIV prevalence among blood donors in Ethiopia [12], declining trend of HIV prevalence among

Table 4 Socio-demographic characteristics of blood donors by HIV and Syphilis sero positivity at Gondar University Teaching Hospital in Northwest Ethiopia 2003-2007

\begin{tabular}{|c|c|c|c|c|c|c|}
\hline Characteristics & $\begin{array}{c}\text { HIV Positive } \\
\text { N (\%) }\end{array}$ & OR $(95 \% \mathrm{Cl})$ & P-Values & $\begin{array}{c}\text { Syphilis Positive } \\
\text { N (\%) }\end{array}$ & OR $(95 \% \mathrm{Cl})$ & P-Values \\
\hline \multicolumn{7}{|l|}{ Age group (years) } \\
\hline $17-25$ & 105/3357 (3.1) & $1.03(0.61-1.74)$ & 0.902 & $31 / 3357(0.9)$ & $0.64(0.30-1.41)$ & 0.271 \\
\hline $26-35$ & 79/1686 (4.7) & 1.57 (0.92 - 2.68) & 0.096 & 28/1686 (1.7) & $1.17(0.53-2.58)$ & 0.702 \\
\hline $36-45$ & $38 / 757(5.0)$ & $1.69(0.94-3.03)$ & 0.077 & 16/757 (2.1) & $1.49(0.63-3.51)$ & 0.359 \\
\hline$>45$ & 17/561 (3.0) & 1.00 & - & 8/561 (1.4) & 1.00 & - \\
\hline \multicolumn{7}{|l|}{ Gender } \\
\hline Male & 188/5592 (3.4) & 1.00 & - & $76 / 5592(1.4)$ & 1.00 & - \\
\hline Female & $51 / 769(6.6)$ & $2.04(1.48-2.81)$ & $<0.001$ & 7/769 (0.9) & $0.67(0.31-1.45)$ & 0.307 \\
\hline \multicolumn{7}{|l|}{ Occupation } \\
\hline Student & $34 / 1347(2.5)$ & 1.00 & - & 9/1347 (0.7) & 1.00 & - \\
\hline Daily labourer & $53 / 1769(3.0)$ & $1.19(0.77-1.85)$ & 0.429 & $38 / 1769(2.1)$ & $3.26(1.57-6.77)$ & 0.001 \\
\hline Farmer & 56/1575 (3.6) & $1.42(0.92-2.19)$ & 0.109 & 20/1575 (1.3) & $1.91(0.87-4.21)$ & 0.108 \\
\hline Housewife & $26 / 212(12.3)$ & $5.40(3.17-9.20)$ & $<0.001$ & $3 / 212(1.4)$ & $2.13(0.57-7.95)$ & 0.258 \\
\hline Govt.employee & $17 / 599$ (2.8) & $1.13(0.63-2.04)$ & 0.689 & 0/599 & - & - \\
\hline Merchant & 23/333 (6.9) & $2.87(1.66-4.93)$ & $<0.001$ & 4/333 (1.2) & $1.81(0.55-5.91)$ & 0.327 \\
\hline Military & 4/47 (8.5) & $3.59(1.22-10.57)$ & 0.020 & $0 / 47$ & - & - \\
\hline Driver & $7 / 120(5.8)$ & $2.39(1.04-5.52)$ & 0.041 & $1 / 120(0.8)$ & $1.25(0.16-9.95)$ & 0.833 \\
\hline Construction worker & 19/359 (5.3) & $2.16(1.22-3.83)$ & 0.009 & $8 / 359(2.2)$ & $3.39(1.30-8.85)$ & 0.013 \\
\hline \multicolumn{7}{|l|}{ Number of donation } \\
\hline First donation & $212 / 4372(4.8)$ & $3.70(2.47-5.55)$ & $<0.001$ & $56 / 4372(1.3)$ & $0.94(0.59-1.50)$ & 0.803 \\
\hline Repeat donation & 27/1989 (1.4) & 1.00 & - & 27/1989 (1.4) & 1.00 & - \\
\hline \multicolumn{7}{|l|}{ HIV status } \\
\hline Positive & - & - & - & 19/239 (7.9) & $8.18(4.81-13.88)$ & $<0.001$ \\
\hline Negative & - & - & - & $64 / 6122(1.0)$ & 1.00 & - \\
\hline
\end{tabular}


Table 5 Socio-demographic characteristics of blood donors by hepatitis B and C virus seropositivity at Gondar University Teaching Hospital in Northwest Ethiopia 2003-2007

\begin{tabular}{|c|c|c|c|c|c|c|}
\hline Characteristics & $\begin{array}{c}\text { HBV Positive } \\
\text { N (\%) }\end{array}$ & OR $(95 \% \mathrm{Cl})$ & P-Values & HCV Positive N (\%) & OR (95\% Cl) & P-Values \\
\hline \multicolumn{7}{|l|}{ Age group (years) } \\
\hline $17-25$ & $144 / 3357(4.3)$ & $1.43(0.86-2.39)$ & 0.166 & 16/2726 (0.6) & $0.91(0.26-3.12)$ & 0.875 \\
\hline $26-35$ & $89 / 1686$ (5.3) & $1.78(1.05-3.02)$ & 0.032 & 13/1395 (0.9) & $1.44(0.41-5.08)$ & 0.569 \\
\hline $36-45$ & 48/757 (6.3) & $2.17(1.23-3.81$ & 0.007 & $3 / 621(0.5)$ & $0.74(0.15-3.71)$ & 0.718 \\
\hline$>45$ & 17/561 (3.0) & 1.00 & - & 3/463 (0.6) & 1.00 & - \\
\hline \multicolumn{7}{|l|}{ Gender } \\
\hline Male & 273/5592 (4.9) & 1.00 & - & $34 / 4528(0.8)$ & 1.00 & - \\
\hline Female & 25/769 (3.3) & $0.66(0.43-0.99)$ & 0.046 & $1 / 677(0.1)$ & $0.20(0.03-1.43)$ & 0.108 \\
\hline \multicolumn{7}{|l|}{ Occupation } \\
\hline Student & 55/1347 (4.1) & 1.00 & - & 6/1188 (0.5) & 1.00 & - \\
\hline Daily labourer & 79/1769 (4.5) & $1.10(0.77-1.56)$ & 0.602 & 8/1312 (0.6) & $1.21(0.42-3.49)$ & 0.726 \\
\hline Farmer & $102 / 1575(6.5)$ & $1.63(1.16-2.28)$ & 0.005 & 14/1293 (1.1) & $2.16(0.83-5.63)$ & 0.117 \\
\hline Housewife & $7 / 212(3.3)$ & $0.80(0.36-1.79)$ & 0.589 & $1 / 179(0.6)$ & $1.11(0.13-9.25)$ & 0.925 \\
\hline Govt.employee & 20/599 (3.3) & $0.81(0.48-1.37)$ & 0.432 & $2 / 525(0.4)$ & $0.75(0.15-3.75)$ & 0.729 \\
\hline Merchant & 12/333 (3.6) & $0.88(0.47-1.66)$ & 0.689 & $0 / 288$ & - & - \\
\hline Military & 2/47 (4.3) & $1.04(0.25-4.42)$ & 0.953 & $0 / 34$ & - & - \\
\hline Driver & 4/120 (3.3) & $0.81(0.29-2.28)$ & 0.689 & $0 / 103$ & - & - \\
\hline Construction worker & $17 / 359(4.7)$ & $1.17(0.67-2.04)$ & 0.585 & $4 / 283(1.4)$ & $2.82(0.79-10.08)$ & 0.110 \\
\hline \multicolumn{7}{|l|}{ Number of donation } \\
\hline First donation & 231/4372 (5.3) & $1.60(1.21-2.11)$ & $<0.001$ & 25/3610 (0.7) & $1.11(0.53-2.31)$ & 0.79 \\
\hline Repeat donation & 67/1989 (3.4) & 1.00 & - & 10/1595 (0.6) & 1.00 & - \\
\hline \multicolumn{7}{|l|}{ HIV status } \\
\hline Positive & $17 / 239(7.1)$ & $1.59(0.96-2.64)$ & 0.07 & 4/181 (2.2) & $3.64(1.27-10.42)$ & 0.02 \\
\hline Negative & 281/6122 (4.6) & 1.00 & - & $31 / 5024(0.6)$ & 1.00 & - \\
\hline
\end{tabular}

OR = Odds ratio; $\mathrm{Cl}=$ Confidence interval; $\mathrm{N}=$ Negative

pregnant women, and declining trend of syphilis infections among pregnant women in Addis Ababa [13]. The initial rise in HIV seroprevalence among the blood donors represents the peak of the epidemic when denial was prevalent and little attention was paid to the disease. The subsequent decline in HIV seroprevalence may be due to the effect of the prevention programs that have been instituted in recent years [14].

The overall seroprevalence of HIV (3.8\%) in this study is similar to the $3.8 \%$ seroprevalence in Ghana [15]. However, it is lower when compared with the $5.5 \%$ in Maiduguri [16], $10.6 \%$ in Nigeria [17] and $16.7 \%$ in Ethiopia [10]. The significantly increased HIV seropositivity among female donors compared to male donors is in accordance with the previous report [18]. This significantly increased HIV seropositivity among female donors might be due to their increased vulnerability to HIV infection as a result of biological, social and economic disadvantages related to their gender [19].

In the present study, the seropositivity rate of HIV and HBV was significantly increased among first time donors compared to repeat donors. This is in agreement with the previous studies [20-22]. The significantly increased HIV and HBV seroprevalence among first time donors might be due to the fact that people who regularly donate blood usually have a profile of low-risk of HIV and HBV infection because they were selected many times [23]. The significantly increased HIV seroprevalence among housewife donors is also consistent with previous study [24] which shows that these women acquired the infection from their partners, who commonly have sexual relations with other women without their partner's knowledge. The partner, considering her relationship to be monogamous, does not use protective methods to avoid infection.

The seroprevalence of HBV (4.7\%) is lower than the previous reports, $10.4 \%$ in Nigeria [25], 15.0\% in Ghana [15] and $14.4 \%$ in Ethiopia [10]. The seroprevalence rate of $\mathrm{HCV}(0.7 \%)$ is in agreement with values ranging between 0 and $1.4 \%$ reported from USA and Europe $[26,27]$ and $0.9 \%$ in Ethiopia [6]. However, it is lower than the $2.8 \%$ in Ghana [28] and the $2.9 \%$ in Port Harcourt [29]. Similarly, the seroprevalence of syphilis $(1.3 \%)$ in this study is lower than the $3.6 \%$ in Maiduguri [23], 7.5\% in Ghana [30], 12.8\% in Ethiopia [31] and $12.7 \%$ in Tanzania [32] but is higher than the $0.1 \%$ 
reported in Port Harcourt [33]. The reason(s) for the relatively lower rate of seroprevalence of $\mathrm{HBV}, \mathrm{HCV}$ and syphilis in this study compared with other studies cannot be discerned. The improvement in technology might make current screening reagents to be more specific and reliable; and could also be a pointer that there are geographical differences in prevalence.

Significantly increased in seroprevalence of HBV was observed in the age groups of $26-35$ and $36-45$ years compared to the age group of greater than 45 years. This is in concurrence with previous reports by Baba et al. [16] and Ejele et al. [33] in which higher prevalence was observed among youths. This observation is worrisome since the most productive and economically viable age group of the populations is worst hit. There is the need for renewed intensification of preventive programmes aimed at high risk behavioural change.

In this study, high prevalence rate of HIV, HBV, HCV and syphilis co-infections was revealed among blood donors. However, none of the donors showed the presence of three or four markers. The HIV - HBV co-infection rate of $17 / 50$ (34\%) and the $19 / 50$ (38\%) HIV - syphilis co-infection observed in this study are higher than the result in Port Harcourt[33] and lower than the $40 \% \mathrm{HIV} / \mathrm{HBV}$ co-infection rate reported by Lodenyo et al. [34]. This high rate of co-infection and the statistically significant relationship between HIV and syphilis, and HIV and HCV infections might be due to the fact that these pathogens share common modes of transmission and risk groups $[6,16,25,35]$.

\section{Conclusion}

A substantial percentage of the blood donors harbour transfusion-transmissible infections, 9.5\% with at least one pathogen and $0.8 \%$ with multiple infections. Transmission of transfusion-transmissible infections during the serologically negative window period still pose a threat to blood safety in environments where there is a high rate of transfusion-transmissible infection. Therefore, strict selection of blood donors with the emphasis on getting voluntary donors and comprehensive screening of donors' blood for HIV, HBV, HCV and syphilis using standard methods are highly recommended to ensure the safety of blood for recipient. The prevalence of HIV, HBV, HCV, and syphilis co-infection needs to be studied on a larger scale for the better understanding of the impact on clinical outcome and treatment response.

\section{Acknowledgements}

We acknowledge all the staff members of blood bank unit, Gondar University Teaching Hospital for the proper documentation of blood donor's information and for their technical support during data collection. Financial support. There was no financial support.

\section{Author details}

${ }^{1}$ Department of Medical Laboratory Technology, College of Medicine and Health Sciences, University of Gondar, Gondar, Ethiopia. ${ }^{2}$ Department of Microbiology and Parasitology, College of Medicine and Health Sciences, University of Gondar, Gondar, Ethiopia. ${ }^{3}$ Division of Allergy and Clinical Immunology, Department of Medicine, University of Colorado Denver, USA. ${ }^{4}$ Department of Medical Laboratory Technology, College of Medicine and Health Sciences, University of Hawassa, Hawassa, Ethiopia. Institute of Clinical Immunology, Faculty of Medicine, University of Leipzig, Leipzig, Germany. ${ }^{6}$ Fraunhofer Institute for Cell Therapy and Immunology, Leipzig, Germany. Institute of Medical Microbiology and Epidemiology of Infectious diseases, Faculty of Medicine, University of Leipzig, Leipzig, Germany.

\section{Authors' contributions}

BT was the primary researcher, conceived the study, designed, participated in data collection, conducted data analysis, drafted and finalized the manuscript for publication. GY, AA and AM assisted in data collection and reviewed the initial and final drafts of the manuscript. AK, FE and US interpreted the results, and reviewed the initial and final drafts of the manuscript. All authors read and approved the final manuscript.

\section{Competing interests}

The authors declare that they have no competing interests.

Received: 23 November 2009 Accepted: 10 May 2010 Published: 10 May 2010

\section{References}

1. Klein HG: Allogenic transfusion risk in the surgical patients. AMJ surg 1995, 170:21-26.

2. UNAIDS: Report on the global AIDS epidemic. Geneva, Joint United Nations program on HIV/AIDS 2002.

3. Fasola FA, Otegbayo IA: Post-transfusion hepatitis in sickle cell anaemia; retrospective-prospective analysis. Nig J Clin Pract 2002, 5:16-19.

4. Drosten C, Nippraschk T, Manegold C, Meisel H, Brixner V, Roth WK, Apedjinov A, Gunther S: Prevalence of Hepatitis B virus DNA in anti-

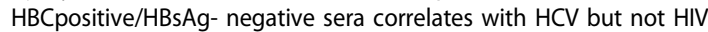
serostatus. J Clin Virol 2004, 29:59-68.

5. Finlayson MDC, Hayes PC, Simpson KJ: Diseases of the liver and biliary system: Hepatitis. Davidson's principles and practice of medicine Churchill Living stone, LondonHaslett C, Chilvers ER, Hunter JAA 1999, 706-715.

6. Ayele W, Nokes DJ, Abebe A, Messele T, Dejene A, Enquselassie F, Tobias F, Wit R, Fontanet A: Higher Prevalence of Anti-HCV Antibodies Among HIVPositive Compared to HIV-Negative Inhabitants of Addis Ababa, Ethiopia. J Med Viro 2002, 68:12-17.

7. Murray P, Rosenthal K, Kobayashi G, Pfaller M: Medical Microbiology. Mosby company, St.Loius, 4 2002, 379-380.

8. Todd J, Munguti K, Grosskurth H, Mngara J, Changalucha J, Mayaud P, Mosha F, Gavyole A, Mabey D, Hayes R: Risk factors for active syphilis and TPHA sero conversion in rural African population. Sex Transm infect 2001, 77:37-45.

9. Temmerman M, Fonck K, Bashir F, Inion I, Ndinya-Achola JO, Bwayo J, Kirui $P$, Claeys $P$, Fransen L: Declining syphilis prevalence in pregnant women in Nairobi since 1995: another success story in STDs. Int J STD AIDS 1999, 10:405-408.

10. Rahlenbeck SI, Yohannes G, Molla K, Reifen R, Assefa A: Infection with HIV, syphilis and hepatitis B in Ethiopia: a survey in blood donors. Int I STD AIDS 1997, 8:261-4.

11. UNAIDS/WHO: Epidemiological Fact Sheets on HIV and AIDS. Ethiopia 2008.

12. Kassu A, Moges F, Mekonnen F, Mengistu G, Abate E, Mekonnen E, Molla K, Zewde T, Assefa A, Wondmikun Y, Ota F: Seroprevalence of human immunodeficiency virus among blood donors in Northwest Ethiopia, 1995-2002. Trop Doct 2006, 36:106-107.

13. Tsegaye A, Rinke de Wit TF, Mekonnen Y, Beyene A, Aklilu M, Messele T, Abebe A, Coutinho R, Sanders E, Fontanet AL: Decline in Prevalence of HIV-1 Infection and Syphilis Among Young Women Attending Antenatal Care Clinics in Addis Ababa, Ethiopia: Results From Sentinel Surveillance, 1995-2001. JAIDS 2002, 30:359-362.

14. Federal Ministry of Health/National HIV/AIDS Prevention and Control Office: AIDS in Ethiopia. Addis Ababa: MOH sixth report 2007. 
15. Ampofo W, Nii-Trebi N, Ansah J, Abe K, Naito H, Aidoo S, Nuvor V, Brandful J, Yamamoto N, Ofori-Adjei D, Ishikawa K: Prevalence of Bloodborne infectious Diseases in blood donors in Ghana. J Clin Microbiol 2002, 40:3523-5.

16. Baba MM, Hassan AW, Gashau W: Prevalence of hepatitis B antigenaemia and human immunodeficiency virus in blood donors in Maidugiri, Nigeria. Niger J Med 2000, 9:10-12.

17. Amadi AN, Mba LE: Distribution of HIV infection in Abia State, Nigeria. Niger J Med Invest Pract 2001, 2:38-40.

18. Kebede D, Aklilu M, Sanders E: The HIV epidemic and the state of its surveillance in Ethiopia. Ethiop Med J 2000, 38:283-302.

19. Bere M, Sunada R: Women and AIDS: Social economic and political factors that increase risk for women. Great Britain, Scot print LTD 1993.

20. Glíuck D, Koerner K, Caspari G, Elbert G, Gaus W, Gríassmann W, Hesse R, Holzberger G, Sternberger J, Vornwald A: Epidemiology of HIV in blood donors in West Germany. Dtsch Med Wochenschr 1988, 113:1383-9.

21. Aymard JP, Janot C, Contal P, Linel C, Monange G, Streiff F: Epidemiologic study of HIV serology in blood donors from 5 departments in northeastern France. Ver Fr Transfus Hemobiol 1989, 32:421-9.

22. Petersen $L R$, Doll $L S$, White $C R$, Johnson $E$, Williams A: Heterosexually acquired human immunodeficiency virus infection and the United States blood supply: considerations for screening of potential blood donors. Transfus 1993, 33:552-557.

23. Chikwem JO, Mohammed I, Okara GC, Ukwandu NC, Ola TO: Prevalence of transmissible blood infections among blood donors at the University of Maiduguri Teaching Hospital, Maiduguri, Nigeria. East Afr Med J 1997, 4:213-6.

24. Szwarewald CL, Bastos FIB, Castilho EA: The dynamics of the AIDS epidemic in Brazil: a space-time analysis in the period 1987-1995. BJID 1998, 2:175-86.

25. Mustapha SK, Jibrin YB: The prevalence of hepatitis B surface antigenaemia in patients with human immunodeficiency virus (HIV) infection in Gombe, Nigeria. Ann Afr Med 2004, 3:10-12.

26. Stevens CE, Taylor PE, Pindyck J: Epidemiology of Hepatitis C virus. J Am Med Assoc 1997, 263:49-53.

27. Sharara Al, Hunt CM, Hamilton JD: Hepatitis C. Ann Intern Med 1996, 125:658-8.

28. Wansbrough-Jones MH, Frimpong E, Cant B, Harris K, Evans MR, Teo CG: Prevalence and genotype of hepatitis $C$ virus infection in pregnant women and blood donors in Ghana. Trans R Soc Trop Med Hyg 1996, 92:496-9.

29. Koate BBD, Buseri Fl, Jeremiah ZA: Seroprevalence of hepatitis $C$ virus among blood donors in Rivers State, Nigeria. Transfus Med 2005, 15:449-51.

30. Adjei AA, Kudzi W, Armah H, Adiku T, Amoah AG, Ansah J: Prevalence of antibodies to syphilis among blood donors in Accra, Ghana. Japanese Infect Dis 2003, 56:165-7.

31. World Health Organization (WHO): Status of blood safety in the WHO African Region: Report of the 2004 Survey WHO Regional Office for Africa. Brazzaville 2007, 1-25.

32. Matee $M$, Magesa $P$, Lyamuya E: Seroprevalence of human immunodeficiency virus, hepatitis $B$ and $C$ viruses and syphilis infections among blood donors at the Muhimbili National Hospital in Dar Es Salaam, Tanzania. BMC Public Health 2006, 6:21-24.

33. Ejele OA, Erhabor O, Nwauche CA: Trends in the prevalence of some transfusion-transmissible infections among blood donors in Port Harcourt, Nigeria. Haema 2005, 8:273-7.

34. Lodenyo H, Schoub B, Ailly R, Kairu S, Segal I: Hepatitis B and C virus infection and liver function in AIDS patients at Chris Hani Baragwanath Hospital, Johannesburg. East Afr Med J 2000, 77:13-15.

35. Mustapha SK, Kudi AA, Asaka LE: Prevalence of hepatitis B surface antigen (HBsAg) and HIV among blood donors in Gombe. J Life Environ Sci 2002, 4:231-235

\section{Pre-publication history}

The pre-publication history for this paper can be accessed here: http://www.biomedcentral.com/1471-2334/10/111/prepub

doi:10.1186/1471-2334-10-111

Cite this article as: Tessema et al:: Seroprevalence of HIV, HBV, HCV and syphilis infections among blood donors at Gondar University Teaching Hospital, Northwest Ethiopia: declining trends over a period of five years. BMC Infectious Diseases 2010 10:111.

\section{Submit your next manuscript to BioMed Central and take full advantage of:}

- Convenient online submission

- Thorough peer review

- No space constraints or color figure charges

- Immediate publication on acceptance

- Inclusion in PubMed, CAS, Scopus and Google Scholar

- Research which is freely available for redistribution

Submit your manuscript at www.biomedcentral.com/submit
Biomed Central 